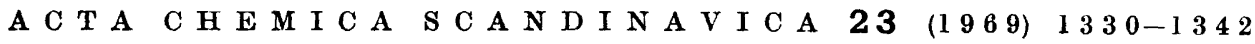

\title{
Studies of Water in Organic Solvents Using NMR and \\ Partition Techniques
}

\author{
LARS ÖDBERG and ERIK HöGFELDT \\ Departments of Physical and Inorganic Chemistry, Royal Institute of Technology (KTH), \\ Stockholm 70, Sweden
}

\begin{abstract}
The chemical shifts and the apparent activity coefficients of water dissolved in $\mathrm{C}_{6} \mathrm{H}_{5} \mathrm{NO}_{2}, \mathrm{C}_{2} \mathrm{H}_{4} \mathrm{Cl}_{2}$, and $\mathrm{C}_{6} \mathrm{H}_{6}$ have been determined as a function of the water activity. For $\mathrm{C}_{6} \mathrm{H}_{5} \mathrm{NO}_{2}$ the results are best understood in terms of a monomer-dimer equilibrium, whereas for $\mathrm{C}_{2} \mathrm{H}_{4} \mathrm{Cl}_{2}$ no conclusive choice could be made between a monomerdimer and a monomer-trimer equilibrium; in both cases, however, the monomer is the dominant species. These conclusions are drawn from the fit of the experimental apparent activity coefficient to the proposed model and from considerations regarding the chemical shifts of the species. In $\mathrm{C}_{6} \mathrm{H}_{6}$ polymeric species are detected only by the NMR technique and can be estimated not to exceed $3.5 \%$ of the total water content.
\end{abstract}

The state of aggregation of water dissolved in various organic solvents
has been studied previously by several methods. From specific volume
and viscosity data Gordon et al. ${ }^{1}$ concluded that water to a large extent is
polymerized in benzene and toluene. However, from partition and solute
isopiestic measurements Högfeldt and Bolander ${ }^{2}$ and Christian et al. ${ }^{3}$ found
that water is predominantly monomeric in these systems. Högfeldt and
Bolander investigated nitrobenzene as well and found for the higher water
activities deviations from monomeric behaviour. Corresponding deviations
were later on found in several organic solvents by Johnson et al. ${ }^{45}$ and Master-
ton and Gendrano ${ }^{6}$ using similar techniques and were by these authors
interpreted as due to formation of polymeric water species. However, for all
solvents investigated the monomer was found to be the predominant molecular
species. In a recent investigation ${ }^{7}$ of the extraction of HCl and HNO 3 by
benzene we have combined the partition technique with a high resolution
NMR-investigation of the organic phase. From this study some further evidence
was obtained indicating that water is monomeric in benzene (e.g. from the
chemical shift of the water protons).
The purpose of the present investigation was to make use of this combina-
tion of the NMR and partition techniques for a detailed investigation of the
molecular state of water in nitrobenzene, 1,2 -dichloroethane, and benzene. 


\section{EXPERIMENTAL}

The samples were prepared and analyzed as described previously by Högfeldt and Bolander. ${ }^{2}$ The purity of the solvents was checked by VPC and was found to be: $\mathrm{C}_{6} \mathrm{H}_{5} \mathrm{NO}_{2}$ $(99.8 \%), \mathrm{C}_{2} \mathrm{H}_{4} \mathrm{Cl}_{2}(99.9 \%)$, and $\mathrm{C}_{6} \mathrm{H}_{6}(99.9 \%)$. The NMR-measurements were carried out using a Varian A-60A apparatus equipped with a Varian variable temperature probe and a Varian variable temperature controller V-6040. The chemical shifts were determined by means of the side-band technique using a Hewlett-Packard 200CD audio oscillator and a Hewlett-Packard 3734A electronic frequency counter. The shift determination was made $3-5$ times for each sample, resulting in a standard deviation of about $\pm 0.1-$ $0.2 \mathrm{c} / \mathrm{s}$. The temperature was kept at $25 \pm 1^{\circ} \mathrm{C}$ in the partition experiments as well as in the NMR-experiments. In the latter experiments the temperature was determined by inserting a small capillary tube containing ethyleneglycol or methanol. The capillary tube was centered in the sample tubes, which allowed the temperature to be determined, while the samples were rotated.

\section{EVALUATION AND PRESENTATION OF THE DATA}

Partition experiments. The equilibrium investigated is:

At equilibrium we have:

$$
\mathrm{H}_{2} \mathrm{O}(\mathrm{aq}) \rightleftharpoons \mathrm{H}_{2} \mathrm{O}(\mathrm{org})
$$

$$
K_{\mathrm{D}}=a_{\mathrm{H}_{2} \mathrm{O}} /\left\{\mathrm{H}_{2} \mathrm{O}\right\}
$$

where $K_{\mathrm{D}}$ is the thermodynamic distribution coefficient and $a_{\mathrm{H}_{2} \mathrm{O}}$ and $\left\{\mathrm{H}_{2} \mathrm{O}\right\}$ are the activities of water in the organic and the aqueous phase, respectively. As the standard state for water in the aqueous phase we chose the pure liquid and for the organic phase we use the definition:

$$
a_{\mathrm{H}_{2} \mathrm{O}} /\left[\mathrm{H}_{2} \mathrm{O}\right] \rightarrow 1 \text { as }\left[\mathrm{H}_{2} \mathrm{O}\right] \rightarrow 0
$$

where $\left[\mathrm{H}_{2} \mathrm{O}\right]$ is the stoichiometric concentration of water in the organic phase (in moles/1). By introducing the corresponding apparent activity coefficient $\gamma_{\mathrm{H}_{3} \mathrm{O}}$

eqn. (2) becomes:

$$
\left[\mathrm{H}_{2} \mathrm{O}\right] \cdot \gamma_{\mathrm{H}_{2} \mathrm{O}}=a_{\mathrm{H}_{2} \mathrm{O}}
$$

$$
\gamma_{\mathrm{H}_{2} \mathrm{O}}=\frac{K_{\mathrm{D}} \cdot\left\{\mathrm{H}_{2} \mathrm{O}\right\}}{\left[\mathrm{H}_{2} \mathrm{O}\right]}
$$

As already mentioned the extraction of water by the organic phase can be described mainly as an extraction of water monomers.

i.e.

$$
\mathrm{H}_{2} \mathrm{O}(\mathrm{aq}) \rightleftharpoons\left(\mathrm{H}_{2} \mathrm{O}\right)_{1}(\mathrm{org})
$$

$$
\left[\mathrm{H}_{2} \mathrm{O}\right]=K_{1}\left\{\mathrm{H}_{2} \mathrm{O}\right\}
$$

The observed deviations from eqn. (7) have been interpreted as due to formation of polymeric species rather than to variations of the activity coefficients for the species in the organic phase. The assumption of formation of polymeric species is given experimental support by the NMR-measurements presented below.

Acta Chem. Scand. 23 (1969) No. 4 
The existence of polymeric water species in the organic phase can be described by the following equilibra:

$$
\begin{aligned}
& 2 \mathrm{H}_{2} \mathrm{O}(\mathrm{aq}) \rightleftharpoons\left(\mathrm{H}_{2} \mathrm{O}\right)_{2}(\text { org }) \\
& 3 \mathrm{H}_{2} \mathrm{O}(\mathrm{aq}) \rightleftharpoons\left(\mathrm{H}_{2} \mathrm{O}\right)_{3} \text { (org) } \\
& \text { etc. }
\end{aligned}
$$

Assuming constant activity coefficients for the various species the total amount of extracted water is:

$$
\left[\mathrm{H}_{2} \mathrm{O}\right]=\sum_{n} \mathrm{n} K_{n}\left\{\mathrm{H}_{2} \mathrm{O}\right\}^{n}
$$

From eqns. (5) and (9) we now obtain:

$$
\gamma_{\mathrm{H}, \mathrm{O}}=\frac{K_{\mathrm{D}}\left\{\mathrm{H}_{2} \mathrm{O}\right\}}{\sum_{n} \mathrm{n} K_{n}\left\{\mathrm{H}_{2} \mathrm{O}\right\}^{n}}
$$

If water is extracted as the two species $\left(\mathrm{H}_{2} \mathrm{O}\right)_{1}$ and $\left(\mathrm{H}_{2} \mathrm{O}\right)_{n}$ a linear variation of $1 / \gamma_{\mathrm{H}_{2} \mathrm{O}}$ with $\left\{\mathrm{H}_{2} \mathrm{O}\right\}^{\mathrm{n}-1}$ is obtained. It is thus possible, in favourable cases, to determine the association number, $n$, and the equilibrium constants from a straight line.

$N M R$-measurements. The water protons in the organic phase give rise to one resonance line only. This does not necessarily indicate, however, that only one species is present, since the proton lifetime at different sites is presumably so short due to rapid rearrangements and possibly also due to proton exchange, that one resonance line at an average position is to be expected. ${ }^{8}$ If the chemical shift between the exchanging sites is very large the rate of exchange may not be sufficiently high to result in a complete averaging and in such a case, a broadening of the observed resonance line can occur. ${ }^{7}$ This effect, however, has not been observed in the present investigation.

For rapid exchange the observed resonance line position is given by ${ }^{8}$

$$
\nu_{\mathrm{obs}}=\sum_{i} \boldsymbol{v}_{i} p_{i}
$$

where $\nu_{i}$ is the resonance frequency for protons at site $i$ and $p_{i}$ is the proton fraction at that site. Assuming that monomers and dimers are formed the observed resonance line position would be

or

$$
v_{\mathrm{obs}}=\frac{K_{1}\left\{\mathrm{H}_{2} \mathrm{O}\right\}}{K_{1}\left\{\mathrm{H}_{2} \mathrm{O}\right\}+2 K_{2}\left\{\mathrm{H}_{2} \mathrm{O}\right\}^{2}} \cdot v_{1}+\frac{2 K_{2}\left\{\mathrm{H}_{2} \mathrm{O}\right\}^{2}}{K_{1}\left\{\mathrm{H}_{2} \mathrm{O}\right\}+2 K_{2}\left\{\mathrm{H}_{2} \mathrm{O}\right\}^{2}} \cdot v_{2}
$$

$$
v_{\mathrm{obs}}=\frac{1}{1+2 K_{2} K_{1}^{-1}\left\{\mathrm{H}_{2} \mathrm{O}\right\}}\left(v_{1}+2 K_{2} K_{1}^{-1}\left\{\mathrm{H}_{2} \mathrm{O}\right\} v_{2}\right)
$$

The expression given by eqn. (13) can be expanded in a series:

$$
v_{\mathrm{obs}}=v_{1}-x\left(\nu_{1}-v_{2}\right)+x^{2}\left(v_{1}-v_{2}\right)+\cdots
$$

where $x=2 K_{2} K_{1}^{-1}\left\{\mathrm{H}_{2} \mathrm{O}\right\}$. If the amount of polymeric species is small, then $x$ is small, and eqn. (14) or corresponding expressions for other combinations of water species can be used to get an idea of the shape of the curve that 
should be expected. It should be noted that in eqn. (12) we have assumed that all the protons in $\left(\mathrm{H}_{2} \mathrm{O}\right)_{2}$ have the same resonance frequency. It is, however, very likely that this condition is fulfilled due to rapid intramolecular proton exchange.

The way we have treated our data is briefly as follows. From the partition measurements we have evaluated the equilibrium constants. The values obtained for these constants were then used to determine the chemical shifts of the different species from the NMR-data. These chemical shifts have been discussed and compared with a proposed molecular model. We have also tried to fit the partition and NMR-data simultaneously by varying all the parameters. However, the covariation was found to be too strong to give a well defined minimum for our experimental material.

We have also measured the chemical shifts for some samples at $43^{\circ} \mathrm{C}$. These measurements are discussed after the subsequent detailed description of the different systems.

\section{RESULTS AND DISCUSSION}

Water-nitrobenzene

Partition experiments. Water solutions of $\mathrm{CaCl}_{2}$ and $\mathrm{LiCl}$ were equilibrated with $\mathrm{C}_{6} \mathrm{H}_{5} \mathrm{NO}_{2}$. From the water content in the organic phase, given in Table 1 , and the water activity in the $\mathrm{CaCl}_{2}{ }^{9}$ and $\mathrm{LiCl}{ }^{10}$ solutions the activity coefficient

Table 1. Solubility of water in nitrobenzene at different water activities.

\begin{tabular}{|c|c|}
\hline Water activity & $\begin{array}{c}\text { Water solubility } \\
\mathrm{mM}\end{array}$ \\
\hline 0.136 & \\
0.349 & 21.3 \\
0.469 & 46.6 \\
0.545 & 67.6 \\
0.593 & 81.4 \\
0.676 & 84.9 \\
0.711 & 101.3 \\
0.750 & 109.1 \\
0.822 & 113.0 \\
0.859 & 128.8 \\
0.875 & 136.1 \\
0.923 & 139.1 \\
0.959 & 147.6 \\
0.989 & 155.0 \\
1.000 & 158.3 \\
\hline
\end{tabular}

was evaluated according to eqn. (5). As the distribution coefficient $K_{\mathrm{D}}$ we have taken the value of $\left[\mathrm{H}_{2} \mathrm{O}\right] /\left\{\mathrm{H}_{2} \mathrm{O}\right\}$ extrapolated to $\left\{\mathrm{H}_{2} \mathrm{O}\right\}=0$ (see eqns. (2) and (3)). The activity coefficients obtained are shown in Fig. 1. Every point is an average of measurements on two different samples. In order to

Acta Chem. Scand. 23 (1969) No. 4 
make the deviations from eqn. (7) easy to recognize we have chosen to illustrate the activity coefficients rather than the solubility of water in $\mathrm{C}_{6} \mathrm{H}_{5} \mathrm{NO}_{2}$, though the fitting of our experimental results to a molecular model was made with respect to the amount of water extracted according to eqn. (9). This fitting procedure was carried out using the least squares program LETAGROPVRID by Sillén and Ingri ${ }^{11}$ adapted to the present problem by Warnqvist. ${ }^{12}$ The following combinations of molecular species were tried: $\mathrm{H}_{2} \mathrm{O}$; $\mathrm{H}_{2} \mathrm{O}$ and $\left(\mathrm{H}_{2} \mathrm{O}\right)_{2} ; \mathrm{H}_{2} \mathrm{O}$ and $\left(\mathrm{H}_{2} \mathrm{O}\right)_{3} ; \mathrm{H}_{2} \mathrm{O}$ and $\left(\mathrm{H}_{2} \mathrm{O}\right)_{4}$. All combinations gave a better fitting than $\mathrm{H}_{2} \mathrm{O}$ alone; the fitting being best for monomers and dimers, getting successively poorer for the higher polymers. We should perhaps also point out that we do not consider our experimental data accurate enough to allow us to fit the data to more than one polymeric species with a reasonable significance.

The resulting values for the monomer dimer description, which are also illustrated in Fig. 1, are

$$
\begin{array}{ll}
\mathrm{H}_{2} \mathrm{O}(\mathrm{aq}) \rightleftharpoons\left(\mathrm{H}_{2} \mathrm{O}\right)_{1}(\mathrm{org}) & K_{1}=(1.24 \pm 0.03) \times 10^{-1} \mathrm{M} \\
2 \mathrm{H}_{2} \mathrm{O}(\mathrm{aq}) \rightleftharpoons\left(\mathrm{H}_{2} \mathrm{O}\right)_{2}(\mathrm{org}) & K_{2}=(1.85 \pm 0.18) \times 10^{-2} \mathrm{M}
\end{array}
$$

The present system has also been studied by Johnson et al., ${ }^{5}$ who also preferred a description in terms of monomers and dimers and from their $K$ values on the mole fraction scale one obtains the following constants:

$$
K_{1}=(1.312 \pm 0.015) \times 10^{-1} \mathrm{M} \quad K_{2}=(1.80 \pm 0.09) \times 10^{-2} \mathrm{M}
$$

i.e. a difference of $3.5 \%$ which is approximately within the limits of the reported uncertainties. It is remarkable that we get the lower values using partition techniques while Johnson et $a .^{5}$ get the higher values using isopiestic measurements. Since our nitrobenzene was $99.8 \%$ pure the differences

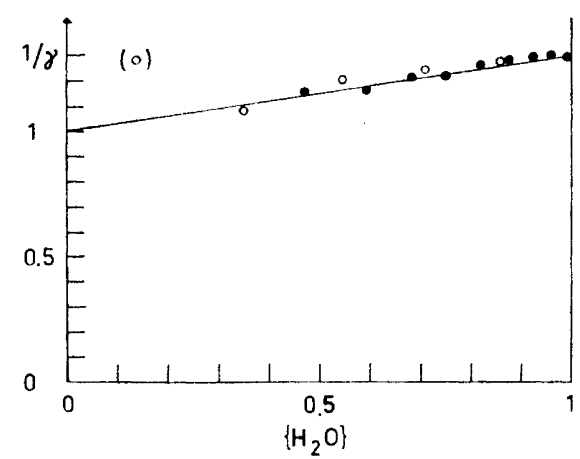

Fig. 1. The inverse of the stoichiometric activity coefficient for water in nitrobenzene $1 / \gamma_{\mathrm{H}_{3} \mathrm{O}}$ versus the water activity in the aqueous phase $\left\{\mathrm{H}_{2} \mathrm{O}\right\}$. $\mathrm{CaCl}_{2}$. experiments; O LiCl-experiments; - calculated from eqn. (10) with constants given by eqn. (15).

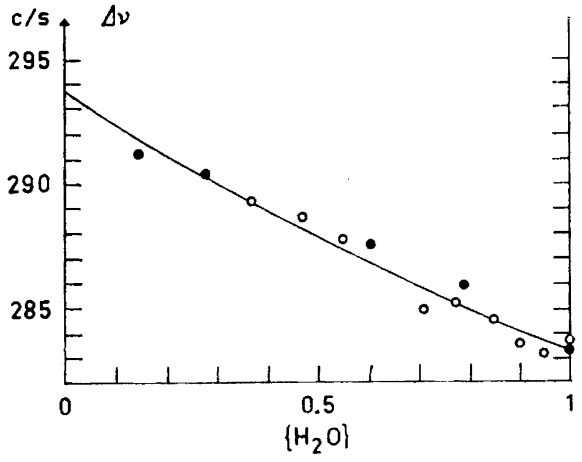

Fig. 2. The chemical shift for the water protons in nitrobenzene relative to benzene as an external standard, $\Delta v$, versus the water activity in the aqueous phase, $\left\{\mathrm{H}_{2} \mathrm{O}\right\}$ LiCl-experiments; $\bigcirc \mathrm{CaCl}_{2}$ experiments; - calculated from eqn. (12) with constants given by eqn. (16).

Acta Chem. Scand. 23 (1969) No. 4 
can hardly be due to impurities in our samples but might be attributed to differences in the methods of water determination.

$N M R$-measurements. The chemical shift of the water protons in the $\mathrm{C}_{6} \mathrm{H}_{5} \mathrm{NO}_{2}$-phase has been determined relative to $\mathrm{C}_{6} \mathrm{H}_{6}$ as an external standard. From eqn. (12) the chemical shift is expected to change with the water activity. This is in fact the case as can be seen from Fig. 2. Every point represents an average of measurements from two different samples. The susceptibility change of the organic solvent due to the dissolved water is far too small to cause any significant line shift. By equilibrating the organic phase with a solution of $\mathrm{AgNO}_{3}$ we have checked that no salt is dissolved into the organic phase along with the water. Such a test was made for all systems and in no case could any traces of $\mathrm{AgCl}$ be observed. The spread in the experimental shifts, which is somewhat greater than the error of determination, reflects their strong temperature dependence ( $c f$. below). We have fitted the chemical shifts obtained to a curve of the form given by eqn. (12) by varying the chemical shifts of the different species while keeping the equilibrium constants fixed. The result for a description with monomers and dimers is (cf. Fig. 2)

$$
v_{1}=v_{\left(\mathrm{H}_{2} \mathrm{O}\right)_{1}}=293.7 \pm 0.3 \mathrm{c} / \mathrm{s} ; \quad v_{2}=v_{\left(\mathrm{H}_{2} \mathrm{O}\right)_{2}}=248 \pm 1 \mathrm{c} / \mathrm{s}
$$

The above chemical shifts, the corresponding shifts in the other systems, the shift for liquid water, determined in a separate experiment, and the shift of water vapor ${ }^{13}$ are compared in Fig. 3. All shifts are given with benzene as

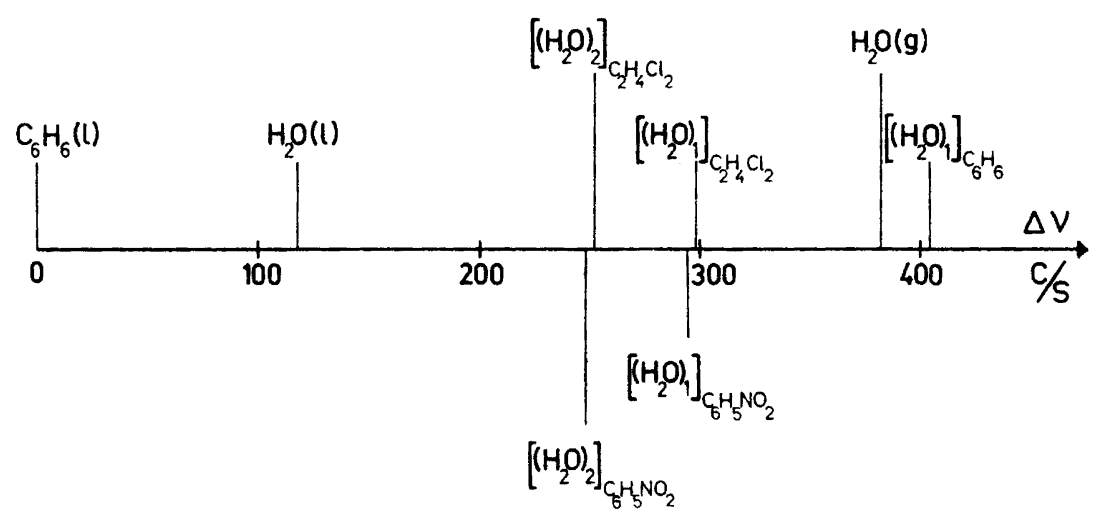

Fig. 3. The chemical shifts for water species in nitrobenzene 1,2-dichloroethane, and benzene relative to benzene. All shifts are corrected for bulk susceptibility differences.

a reference and are also corrected for bulk susceptibility differences between the different solvents. Anticipating the subsequent discussion of the shifts given by eqn. (16) we remark that the water resonance line position in nitrobenzene and in the other systems as well is far removed from the resonance line for pure water. This observation obviously indicates that water is not highly associated in these solvents. 
As compared to a free water molecule in the vapor phase, a water monomer in nitrobenzene is most probably affected by hydrogen bonding to the nitro groups as is reflected in the high water solubility in nitrobenzene. Such an interaction gives rise to a hydrogen bonding shift to lower field (i.e. towards the benzene reference). ${ }^{13}$ In an aromatic solvent the dissolved molecules preferably occupy positions above and below the plane of the ring. The ring current induced in the aromatic molecules ${ }^{14}$ causes in this case a shift to higher field for the dissolved molecules that we shall call in the following the aromatic solvation shift. ${ }^{15}$ Both these effects can be of considerable magnitude $(100 \mathrm{c} / \mathrm{s})$. In order to account completely for the effect of the solvent on the chemical shift of the dissolved molecule we should also, following Buckingham et al., ${ }^{16}$ include the terms $\sigma_{\mathrm{w}}$ and $\sigma_{\mathrm{E}}$, i.e. the effect due to the van der Waals forces between the solute and solvent molecules and the contribution due to the electric field of the dipole moment of the dissolved molecule. Both these effects cause a decrease of the shielding of the dissolved molecule and yield shifts to lower field amounting to $10-20 \mathrm{c} / \mathrm{s}$ each.

Reeves and Schneider ${ }^{17}$ studied the chemical shift of chloroform in different aromatic solvents. They found that the aromatic solvation effect normally was the predominant effect. However, for nitrobenzene it was approximately cancelled by the effect of hydrogen bonding. If we make the reasonable assumption that hydrogen bonding is of greater relative importance for the water-nitrobenzene system, the observed resonance line position for the water monomer in nitrobenzene is readily understood.

Let us suppose that the water dimer has a linear structure, according to Fig. 4.<smiles>O=CO</smiles>

Fig. 4. Proposed structure for the water dimer.

In this molecule one hydrogen is taking part in a hydrogen bond between the water molecules, whereas the other three hydrogens have properties similar to those in the monomer. In order to obtain an estimate of the resonance frequency of the dimer we assume that the resonance frequency for the hydrogen bonded proton is equal to the proton resonance frequency of liquid water (Fig. 3) and that the resonance frequency of the other protons equals the resonance frequency of the monomer. Accordingly

$$
\begin{aligned}
& v_{\left(\mathrm{H}_{2} \mathrm{O}\right)_{2}}=\frac{1}{4} v_{\mathrm{H}_{2} \mathrm{O}(1)}+\frac{3}{4} \nu_{\left(\mathrm{H}_{2} \mathrm{O}\right)_{1}} \\
& =\frac{1}{4} \times 117.2+\frac{3}{4} \times 293.7=249 \mathrm{c} / \mathrm{s}
\end{aligned}
$$

As can be seen the agreement with the experimental result is even better than could be expected from using this simplified calculation method. From our partition and NMR-measurements we have in an analogous way evaluated the chemical shifts supposing that the system can be described in terms of monomers and trimers. The result is:

$$
v_{\left(\mathrm{H}_{2} \mathrm{O}\right)_{1}}=291.6 \pm 0.2 \mathrm{c} / \mathrm{s} ; v_{\left(\mathrm{H}_{2} \mathrm{O}\right)_{3}}=240 \pm 2 \mathrm{c} / \mathrm{s}
$$


By reasoning similar to those in eqn. (17) a linear trimer should have a shift of $233 \mathrm{c} / \mathrm{s}$.

We may thus conclude that the partition data as well as the NMR data are best interpreted in terms of a monomer-polymer equilibrium, such that the polymer concentration is much less than the monomer concentration. The polymeric species fitting the available data best is the dimer.

It would be tempting to speculate on the detailed structure of the various complexes. We do, however, consider the experimental material insufficient as yet, and it should also be noted that what we have simply written as $\left(\mathrm{H}_{2} \mathrm{O}\right)_{1}$ $\left(\left(\mathrm{H}_{2} \mathrm{O}\right)_{2} ;\left(\mathrm{H}_{2} \mathrm{O}\right)_{3} \ldots\right)$ might very well consist of an equilibrium mixture of various structures.

\section{Wat e r-1,2-dich loroet hane}

Partition experiments. The same measurements as for $\mathrm{C}_{6} \mathrm{H}_{5} \mathrm{NO}_{2}$ were performed. The results are given in Table 2 and Fig. 5. As can be seen from Fig. 5 and as has been claimed by Johnson et al. ${ }^{4}$ and Masterton and Gendrano, ${ }^{6}$

Table 2. Solubility of water in 1,2-dichloroethane at different water activities (taken from a smoothed curve).

\begin{tabular}{|c|c|}
\hline Water activity & $\begin{array}{c}\text { Water solubility } \\
\mathrm{mM}\end{array}$ \\
\hline 0.178 & 20.7 \\
0.224 & 27.0 \\
0.282 & 32.8 \\
0.355 & 40.5 \\
0.447 & 50.3 \\
0.562 & 62.2 \\
0.631 & 70.5 \\
0.708 & 80.3 \\
0.794 & 92.6 \\
0.841 & 99.0 \\
0.991 & 106.5 \\
1.000 & 114.0 \\
\hline
\end{tabular}

the observed deviations from eqn. (7) are smaller for this system as compared to the $\mathrm{H}_{2} \mathrm{O}-\mathrm{C}_{6} \mathrm{H}_{5} \mathrm{NO}_{2}$ system.

Using the same program as before we have tried to fit our data to different models, such that the water exists as monomers or monomers and polymers (up to tetramers). Again the fitting is better for any of the combinations than for monomers alone, monomers + dimers and monomers + trimers being the best and being equally good within a few percent as determined from the error square sum. When the effect of the polymer on the apparent activity coefficients is as small as in the present system, a comparatively large deviation in one single point may severely effect the results. We therefore drew a smoothed curve through our experimental points. When the association constants Acta Chem. Scand. 23 (1969) No. 4 


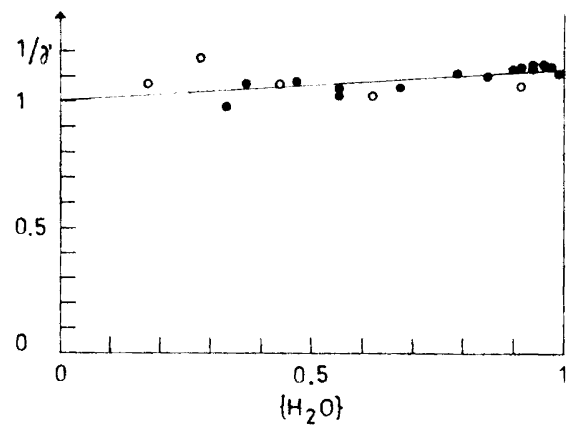

Fig. 5. The inverse of the stoichiometric activity coefficient for water in 1,2 . dichloroethane, $1 / \gamma_{\mathrm{H}_{2}} \mathrm{O}$, versus the water activity in the aqueous phase $\left\{\mathrm{H}_{2} \mathrm{O}\right\}$. - $\mathrm{CaCl}_{2}$-experiments; O LiCl-experiments; - calculated from eqn. (10) with constants given by eqn. (19).

were determined from this curve we obtained slightly different constants and in this case the error square sum was $25 \%$ less for the trimer than for the dimer assumption, the two sets of equilibrium constants being:

$$
\begin{aligned}
& K_{1}=(1.07 \pm 0.03) \times 10^{-1} \mathrm{M} \\
& K_{2}=(6.8 \pm 1.6) \times 10^{-3} \mathrm{M}
\end{aligned} \quad \text { (19) } \begin{aligned}
& K_{1}=(1.10 \pm 0.01) \times 10^{-1} \mathrm{M} \\
& K_{3}=(3.8 \pm 0.7) \times 10^{-3} \mathrm{M}
\end{aligned}
$$

The set of equilibrium constants given by eqn. (19) is illustrated by the full drawn curve in Fig. 5.

For this system Johnson et al. ${ }^{4}$ preferred a description with trimers or tetramers giving for the trimers

$$
K_{1}=(1.083 \pm 0.02) \times 10^{-1} \mathrm{M} \quad K_{3}=(5.8 \pm 1.2) \times 10^{-3} \mathrm{M}
$$

and stated that their data could not be fitted within experimental error to a dimeric description. Masterton and Gendrano, ${ }^{6}$ however, claimed that their data for the same system can be equally well explained by either a monomerdimer or a monomer-trimer equilibrium. We have recalculated their data using our program and found that the fitting is somewhat better for the monomer-dimer combination which is also the one for which their equilibrium constants, viz.

$$
K_{1}=1.131 \times 10^{-1} \mathrm{M}
$$

$$
\begin{aligned}
K_{2}= & 6.9 \times 10^{-3} \mathrm{M} \\
& (\text { av.dev } . \pm 0.0002)
\end{aligned}
$$

are given.

Considering the small amounts of polymeric species present in this system we do not find it surprising that more than one set of equilibrium constants can adequately account for the thermodynamic measurements.

$N M R$-measurements. The chemical shift of water in dichloroethane at various water activities measured relative to dichloroethane as an internal standard is given in Fig. 6. The resonance line position of dichloroethane was checked relative to $\mathrm{C}_{6} \mathrm{H}_{6}$ as our external standard. The varying chemical shift indicates the existence of more than one species in the organic phase. Using the method outlined for nitrobenzene we have calculated the chemical shifts for the various combinations. The results are given in Table 3 (relative to benzene). 
Table 3. Chemical shifts relative to benzene in 1,2-dichloroethane, $t=25^{\circ} \mathrm{C}$ for different assumptions of existing polymeric water species.

\begin{tabular}{|c|c|c|}
\hline $\begin{array}{c}\text { Species } \\
\mathrm{H}_{2} \mathrm{O} ;\left(\mathrm{H}_{2} \mathrm{O}\right)_{n}\end{array}$ & $\begin{array}{c}v_{1} \\
\mathrm{c} / \mathrm{s}\end{array}$ & $\begin{array}{c}v_{n} \\
\mathrm{c} / \mathrm{s}\end{array}$ \\
\hline & & \\
$\mathrm{H}_{2} \mathrm{O} ;\left(\mathrm{H}_{2} \mathrm{O}\right)_{2}$ & $297.7 \pm 0.1$ & $251.9 \pm 1.4$ \\
$\mathrm{H}_{2} \mathrm{O} ;\left(\mathrm{H}_{2} \mathrm{O}\right)_{3}$ & $296.4 \pm 0.1$ & $250.1 \pm 0.9$ \\
$\mathrm{H}_{2} \mathrm{O} ;\left(\mathrm{H}_{2} \mathrm{O}\right)_{4}$ & $296.0 \pm 0.1$ & $248.5 \pm 2.4$ \\
\hline
\end{tabular}

As can be seen from Fig. 3 the chemical shift of the monomer is about $100 \mathrm{c} / \mathrm{s}$ shifted towards lower field relative to the water vapor. This shift can be readily understood in terms of the $\sigma_{\mathrm{E}^{-}}$and $\sigma_{\mathrm{W}}$-effects and the assumption that the water molecule is weakly hydrogen bonded to the chlorine atoms which is also reflected in the relatively high solubility of water in dichloroethane. The shifts of the various linear polymeric species can again be estimated in accordance with eqn. (17). For a linear dimer we get $253 \mathrm{c} / \mathrm{s}$, for a trimer $237 \mathrm{c} / \mathrm{s}$ and for a tetramer $230 \mathrm{c} / \mathrm{s}$. Comparing these figures to those in Table 3 it is seen that a monomer-dimer description is favoured. However, we must also consider the possibility of the existence of cyclic polymeric species. In a cyclic species (e.g. a trimer) the hydrogen bonded protons are no longer on the line connecting the oxygen atoms and this will lead to weaker hydrogen bonds. We can then no longer approximate the resonance frequency of this hydrogen bonded proton to the resonance frequency of liquid water, but must instead use a resonance frequency that is shifted towards higher field. If this latter chemical shift is used we might very well obtain a calculated chemical shift

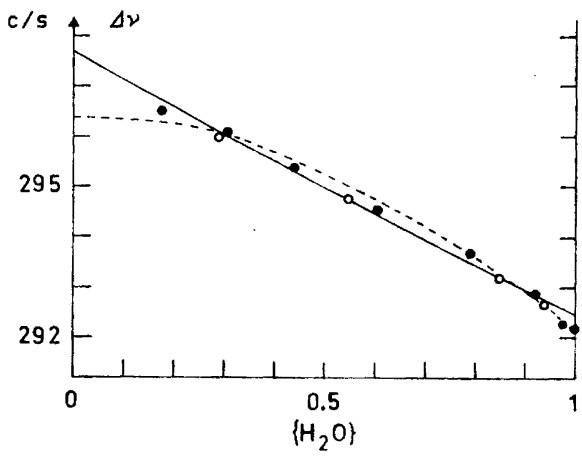

Fig. 6. The chemical shift for the water protons in 1,2-dichloroethane relative to benzene as an external standard, $\Delta v$, versus the water activity in aqueous phase, $\left\{\mathrm{H}_{2} \mathrm{O}\right\}$, LiCl-experiments; O $\mathrm{CaCl}_{2}$ experiments; - calculated from eqn. (12) with $\nu_{1}$ and $v_{2}$ given in Table 3 ; _ - calculated from eqn. (12) with $v_{1}$ och $v_{3}$ given in Table 3 .

Acta Chem. Scand. 23 (1969) No. 4

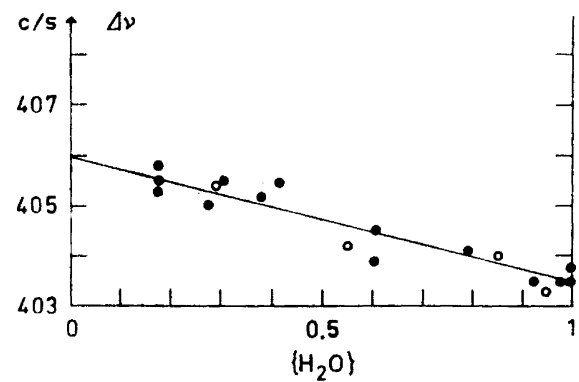

Fig. 7. The chemical shift for the water protons in benzene relative to benzene as an internal standard, $\Delta v$, versus the water activity in the aqueous phase, $\left\{\mathrm{H}_{2} \mathrm{O}\right\}$. 
in agreement with the experimental one in Table 3. It should also be observed from Table 3 and Fig. 6 that the agreement with the experimental chemical shifts is best for the monomer-trimer description. During an investigation of the hydration of acetone in 1,2-dichloroethane Lin et al. ${ }^{18}$ also measured the resonance frequency for water in dichloroethane and used the assumption of the existence of cyclic trimers to explain their results.

From the presented observations we have clear indications that water is to some degree associated in 1,2-dichloroethane. The polymeric species suggested by us are a linear dimer or a cyclic trimer (or both). We do, however, not regard the available data sufficient to make a conclusive choice between these two.

B enzene-water

Partition experiments. Earlier measurements ${ }^{2-4,6,7}$ as well as this investigation have shown that the apparent activity coefficient of water in benzene stays constant within the estimated experimental error at these low water concentrations. This result implies that water exists in benzene as monomers.

NMR-measurements. The results from the analogous NMR-measurements for this system are shown in Fig. 7. The low water concentrations in this system yield a very low signal to noise ratio that makes it difficult to determine the chemical shifts to much better than $\pm 0.5 \mathrm{c} / \mathrm{s}$. As is seen from Fig. 7 there is in fact a variation of the resonance line position with the water activity in the aqueous phase also in this system, indicating the formation of polymeric species.

If the chemical shift of a dimer is calculated as previously we get $v_{\left(\mathrm{H}_{8} \mathrm{O}\right)_{\mathrm{s}}}=334 \mathrm{c} / \mathrm{s}$. From this figure we find that the highest fraction of water present as dimers, at unit activity, would be $3.5 \%$, an amount which is hard to detect by the techniques used so far. Other species than the linear dimer would give an even lower fraction of polymers. Thus our observation of a rather small degree of association can therefore hardly be considered to be in contradiction with the earlier thermodynamic measurements.

The resonance line position for the water monomers in benzene is shifted $26 \mathrm{c} / \mathrm{s}$ towards higher field relative to water vapor ( $c f$. Fig. 3). The van der Waals and dipole effects cause shifts to lower field but the aromatic solvation shift gives a shift to higher field which more than cancels this. A highly polymerized species would have very high contributions to the chemical shift from hydrogen bonding and seems therefore very improbable also from the NMR-measurements.

\section{Temperature effects}

Before investigating the effect of temperature on the water signal in our systems we checked the influence of temperature on our reference substances by measuring the shift of $\mathrm{C}_{2} \mathrm{H}_{4} \mathrm{Cl}_{2}$ relative to $\mathrm{C}_{6} \mathrm{H}_{6}$ at the two selected temperatures.

$\begin{array}{cc}\text { Temp. } & v_{\mathrm{C}_{2} \mathrm{H}_{4} \mathrm{Cl}_{2}} \\ 25^{\circ} \mathrm{C} & 155.9 \\ 43^{\circ} \mathrm{C} & 157.8\end{array}$

Acta Chem. Scand. 23 (1969) No. 4 
The temperature rise is likely to shift the benzene signal to lower field, due to a weakening of the anisotropy, i.e. the aromatic solvation shift, with the more rapid motions of the benzene molecules. This temperature effect is somewhat analogous to the observed dilution shifts of aromatics. In a first approximation we thus consider the $\mathrm{C}_{2} \mathrm{H}_{4} \mathrm{Cl}_{2}$ signal to be temperature independent.

The chemical shifts of the water protons in the samples equilibrated with pure water are given in Table 4.

Table 4. The chemical shift of water in organic solvents at $t=25^{\circ} \mathrm{C}$ and $t=43^{\circ} \mathrm{C}$.

\begin{tabular}{|l|c|c|c|}
\hline \multirow{2}{*}{ Organic solvent } & \multicolumn{2}{|c|}{ Shift c/s } & $\begin{array}{c}\text { Reference } \\
\text { substance }\end{array}$ \\
\cline { 2 - 4 } & $25^{\circ} \mathrm{C}$ & $43^{\circ} \mathrm{C}$ & \\
\hline & 283.5 & 292.5 & $\mathrm{C}_{6} \mathrm{H}_{6}$ \\
$\mathrm{C}_{6} \mathrm{H}_{8} \mathrm{NO}_{2}$ & 127.5 & 130.5 & $\mathrm{C}_{2} \mathrm{H}_{4} \mathrm{Cl}_{2}$ \\
$\mathrm{C}_{2} \mathrm{H}_{4} \mathrm{Cl}_{2}$ & 403.5 & 403.2 & $\mathrm{C}_{6} \mathrm{H}_{6}$ \\
\hline
\end{tabular}

Nitrobenzene. We have a pronounced shift to higher field depending on weakened hydrogen bonds between water and nitrobenzene and weakened hydrogen bonds between water molecules $\left(\left(\mathrm{H}_{2} \mathrm{O}\right)_{2} \rightarrow 2\left(\mathrm{H}_{2} \mathrm{O}\right)_{1}\right)$. The observed temperature effect may be further increased due to unequal weakening with temperature of the aromatic solvation effects for the reference protons in benzene and the water protons in nitrobenzene.

1,2-Dichloroethane. Here, too, we have a shift towards higher field probably due to dimer dissociation and to weakened hydrogen bonds between dichloroethane and water.

Benzene. The water shift is almost independent of temperature. The expected effect is of the order of $1 \mathrm{c} / \mathrm{s}$. Such an effect is difficult to observe and can also be hidden by a small difference in the weakening of the aromatic solvation effect for the benzene protons and the water protons.

These observations concerning the temperature effects thus lend qualitative support to the interpretation of the data given above.

Acknowledgements. We would like to thank Mr. Folke Fredlund for his careful preparation and analysis of the samples. Drs. Erik Forslind, L. G. Sillén, and J. C. Eriksson are thanked for valuable discussions. Helpful comments on the manuscript were also made by Mrs. Barbro Maijgren. Mr. Ashley Stevens corrected the English of the text.

Financial support was given by the Swedish Natural Science Research Council and Swedish Council for Applied Research. 


\section{REFERENCES}

1. Gordon, M., Hope, C., Loan, L. and Roe, R. Proc. Roy. Soc. A 258 (1960) 215.

2. Högfeldt, E. and Bolander, B. Arkiv Kemi 21 (1963) 161.

3. Christian, S. D., Affsprung, H. E. and Johnson, J. R. J. Chem. Soc. 19631896.

4. Johnson, J. R., Christian, S. D. and Affsprung, H. E. J. Chem. Soc. A 196677.

5. Johnson, J. R., Christian, S. D. and Affsprung, H. E. J. Chem. Soc. A 19671924.

6. Masterton, W. L. and Gendrano, M. C. J. Phys. Chem. 70 (1966) 2895.

7. Eriksson, J. C., Ödberg, L. and Högfeldt, E. Acta Chem. Scand. 21 (1967) 1925.

8. Pople, J. A., Schneider, W. G. and Bernstein, H. J. High-resolution Nuclear Magnetic Resonance, McGraw, New York 1959, p. 221.

9. Robinson, R. A. and Stokes, R. H. Electrolyte Solutions, 2nd Ed., Butterworth, London 1959, p. 478.

10. Ref. 9, p. 491 .

11. Ingri, N. and Sillén, L. G. Arkiv Kemi 23 (1964) 97.

12. Warnqvist, B. Personal communication.

13. See Ref. 8, Ch. 15.

14. See, e.g., Ref. 8, p. 180.

15. Ref. 8, p. 428 .

16. Buckingham, A. D., Schaefer, T. and Schneider, W. G. J. Chem. Phys. 32 (1960) 1227.

17. Reeves, L. W. and Schneider, W. G. Can. J. Chem. 35 (1957) 251.

18. Lin, T. F., Christian, S. D. and Affsprung, H. E. J. Phys. Chem. 69 (1965) 2980.

Received October 3, 1968. 